\title{
Treatment Costs for Nasopharyngeal Cancer by Stages: Patients' Experience in Sarawak General Hospital
}

\author{
Choi-Yean Yeoh ${ }^{1}$, Chin-Hong Puah ${ }^{1}$, Rayenda Khresna Brahmana ${ }^{1}$, Shirly Siew-Ling Wong ${ }^{1} \&$ Harry Entebang ${ }^{1}$ \\ ${ }^{1}$ Faculty of Economics and Business, Universiti Malaysia Sarawak, Kota Samarahan, Malaysia \\ Correspondence: Chin-Hong Puah, Faculty of Economics and Business, Universiti Malaysia Sarawak, 94300 Kota \\ Samarahan, Sarawak, Malaysia. Tel: 60-8258-4294. E-mail: chpuah@unimas.my
}

Received: October 14, 2019

Accepted: December 4, 2019

Online Published: June 15, 2020

doi:10.5430/rwe.v11n3p26

URL: https://doi.org/10.5430/rwe.v11n3p26

\begin{abstract}
The study investigates an average direct and indirect costs incurred by Nasopharyngeal Cancer (NPC) patients who received diagnosis, treatment and follow up in the Sarawak General Hospital, Kuching, Malaysia. A total of 299 NPC patients were randomly selected using a primary data collection approach from the Sarawak General Hospital between November 2018-March 2019. Information related to the average direct and indirect costs incurred by NPC patients at various stages and the sources of their financial assistance throughout the treatment periods were assorted. The study reveals that the total average cost of 169 or $56.52 \%$ of the NPC patients who received various treatment services in the public hospital is RM13,165 against RM78,860 on 130 or $43.48 \%$ of the patients received the same services in both public and private healthcare. Major sources of funding come from patients' savings, family members, medical insurances, non-profit organization or charity, company healthcare benefits, employees' provident fund (EPF) as well as subsidy from the government: This study suggests that the treatment cost for cancer patient is high and hence, there is a need to establish a mechanism that can provide a free screening test for NPC as a forward step to cancer prevention, while for policy makers to develop a more supportive initiative to address the needs of the poor patients.
\end{abstract}

Keywords: nasopharyngeal cancer, average direct and indirect costs, financial burden, sources of funding

\section{Introduction}

Nasopharyngeal Cancer (NPC) is a type of nasopharynx cancer and has been regarded as highly associated with Epstein- Barr Virus (EBV) occurred at the back of the nose and above the soft palate (Bernama, 2018b; Lau, 2018). Nasopharyngeal cancer risk factors may include family history of NPC, heavy intake of preserved food such as salted fish and vegetables, reactivation of Epstein-Barr virus (EBV), smoking, occupational exposure to wood dust, formaldehyde, chemical fumes, including the practice of burning incense sticks (Devi et al., 2004; Mai et al., 2019). Past studies also highlighted that NPC symptoms may include cervical lymphadenopathy, epistaxis, loss of hearing, and diplopia (Tiong \& Selva, 2005; Adham et al., 2012; Al-Azri \& Al-Sheibani, 2015). In fact, eighty-eight percent of patients diagnosed with cervical lymphadenopathy (neck swollen) are very likely (85 percent) to have developed NPC. The growth of NPC becomes prevalent after three weeks of painless swelling or lumping in the upper throat and generally this can be discovered on the right than either left side or both sides. Epistaxis (bleeding of the nose) won't be a one-time event and the bleeding will continue as the patient continually blows the nose. However, due to its non-specific symptoms, NPC is hard to be examined clinically, hence more than $70 \%$ of the cases are late-stage cases (Wu et al., 2016).

In Malaysia, cancer is the fourth most common cause of death with roughly 37,000 cases annually (MySCan, 2018). In 2018, Malaysia recorded a total death toll of 26,395 while registering a total of 43,837 new cancer cases (Bray et al., 2018). According to MySCan, the number of cancer patients in Malaysia will rise to more than 55,000 cases annually by 2030 (MySCan, 2018). For both sexes, breast cancer, colorectal cancer, lung cancer, nasopharyngeal cancer and liver cancer are the top five most common cancers excluding the non-melanoma skin cancer (ranked by cases) in Malaysia. In fact, NPC is the fourth most frequent cancer suffered by Malaysians and, the third most frequent cancer suffered by Malaysian males (Ministry of Health Malaysia, 2015). Given this, Malaysia has an alarming high rates of NPC incidence in the world, especially in Sarawak (Devi et al., 2004; Tiong \& Selva, 2005; Jong et al., 2019). 
In 2018, the Sarawak General Hospital reported that there are 1,991 new cancer cases with 20,713 classified under follow-up cases (Radiotherapy and Oncology Unit, 2018). In particular, Nasopharyngeal cancer is one of the top four type of cancer suffered by Sarawakians (Lim, 2002; Lau, 2017). According to the Radiotherapy and Oncology Unit (RTU), a division of the Sarawak General Hospital, a total of 188 newly diagnosed NPC cases were reported in 2018 with 138 male and 50 female patients accordingly. Specifically, about $80 \%$ of the NPC patients are from Kuching and Serian Divisions (Tiong \& Selva, 2005). A Bidayuh community who are mostly reside in Serian Division has the highest of NPC rates in the globe, followed by Hong Kong and Singaporean Chinese and all other Sarawak Dayak races including Chinese in Sarawak (Lau, 2018). Recognizing this, Malaysia offers a unique research setting for the Nasopharyngeal Cancer (NPC) treatment-care cost related issues.

As implied by the recent term "financial toxicity," cancer treatment leads to financial predicament in any family. The real truth about cancer is that cancer is not only fatal, but once it has attacked a person's life, it is costly to be treated and in fact, the success rate to overcome this form of critical disease is very low. On the other hand, the medical inflation rate in Malaysia showed a steady rise from 2016. For instance, it rose from $11.8 \%$ in 2017 to $12.6 \%$ and struck $13.2 \%$ in 2018 (Sedek, 2019).

In treating cancer disease, both direct and indirect medical costs should be considered. Direct medical costs require medical services transaction which may include items such as physician services, diagnostic testing, and hospitalization expenditures. On the other hand, the indirect financial implications of NPC have been poorly explained as compared with the delineation of direct costs involved with NPC therapy. In fact, indirect costs such as travelling, accommodation, alternative therapy, home services and patient or caregiver loss of income and productivity associated to cancer morbidity and mortality can paralyze the financial situation of a person or a family (Sherman et al., 2001; Mossanen \& Gore, 2014). This kind of financial toxicity is both an objective physical burden and an increased subjective economic poverty that not only brings the patient economic strain, but also the well-being of their life and family members (Ubel, 2010). Indebtedness becomes prevalent and can be serious if the person with cancer belongs to the low-and middle-income group and is not well-insured or covered. Even though the state government does support the patient with healthcare facilities through the provision of free/subsidized hospital therapy, patients still suffer from the elevated price of indirect costs. Study showed 45 percent of patients with Malaysian cancer suffer from an "economic disaster" 12 months after diagnosis.

Studies to estimate both direct and indirect costs in treating NPC cancer in Sarawak, Malaysia remains limited in the public domain. Notably, the cost of treatment in both government and private hospitals varies significantly. The aims of the study, therefore, was to quantify the direct and indirect costs incurred by them through the experience of patients suffered by Nasopharyngeal cancer, efforts have been intensified. In addition, the demographic characteristics, cancer condition, hospital and treatment choices, sources help to reduce their financial burden, and difficulties faced by patients during treatment of Nasopharyngeal cancer patients are reported in this study.

\section{Literature Review}

Sarawak is the largest state in Malaysia with 12 divisions. Up to 2010, a total of 2,471,140 in total population was recorded. Kuching is the largest division with 705,546 populations, followed by Miri with 364,561 populations (Department of Statistics, 2010). Serian is the second-lowest division with 91,599 population (Department of Statistics, 2010). In terms of ethnic group in Sarawak (2010), Iban registered a total number of 713,421, followed by Chinese, 577,646; Malay, 568,113; Bidayuh, 198,473; Orang Ulu,156,436; Melanau, 123,410; and Others, 16,549 and these ethic groups formed the major ethnic groups in Sarawak in 2010 (Kheung \& Adruce, 2018). Notably, past studies also have found that Sarawak has high risk of NPC occurrence (Devi et al, 2004; Yeo et al., 2018) while remain as the second highest poverty rate $(0.61 \%)$ in Malaysia (CEIC, 2016).

According to Yeo et al. (2018), a total of 1,102 newly diagnosed NPC cases were registered from 2010-2016. The outcomes of the study revealed another finding which defers from the study by Lau (2018). Yeo et al., (2018) argue that NPC cases in the state appears to reflect the demographic composition of the population. The study shows that the Iban ethnicity make up of $31 \%$ of the total NPC cases reported and this is followed by Chinese (23\%), Bidayuh (20\%) and other races. On the other hand, most of the NPC cases were recorded in Kuching with 309 (28\%) cases, followed by Serian 163 (14.8\%), and Miri 154 (14\%). However, Serian recorded the highest NPC crude rate among the 12 divisions (25.4) in Sarawak, and in particular, male and female respectively had a crude rate of 37.1 and 13.3. Notably, the study posits that the elevated incidence of NPC in Kuching and Miri divisions could be due to higher population. However, the total population in Serian remains low and yet the division recorded the largest crude rate in the state with 91 patients had NPC family history. According to Devi et al. (2004), men have higher risk in getting NPC than women and the age-adjusted rate (ASR) in Sarawak residents was 13.5/100,000 with 95\% confidence 
interval (CI) 12.2-15.0 and 6.2/100,000 with 95\% confidence interval (CI) 5.7-6.7 respectively in both men and women.

Even though the Bidayuh has been regarded as one of the world's leading incidence ethnic / ASR of NPC, however, past evidences have associated the claim with the elevated incidence of family history of NPC, and both findings were supported by Devi et al. (2004) and Yeo et al. (2018). In fact, past studies highlight that the risk in the Bidayuh community was 2.3 -fold (M) and 1.9-fold (F) higher than the average risk of the state, and about $50 \%$ higher than Hong Kong. Given this, the risk of the Bidayuh community to suffer from NPC has recorded the highest for the same era by any population-based registry. In addition, MySCan (2018) reports that an international comparison with other study by Zeng, et al (2018) showed that the overall 5-year relative NPC survival in Malaysia is $46.0 \%$ from the period of diagnosis between 2007-2011 and the followed up was done in 2016 and the finding was higher than China (43.8\%, incidence 2009-2011). However, the 5year relative survival by sex (males: $44.8 \%$, females: $49.2 \%$ ) is lower than Singapore (males: $58.5 \%$, females: 60.4\%) for incidence recorded between 2008-2012 (National Registry of Diseases Office, 2015).

According to the WHO, the total annual financial costs due to cancer were estimated at US\$ 1.16 trillion in 2010 (WHO, 2018) and the costs may go double by 2020. In India, the costs of NPC usually cost between Rs 115,000-20,000 a month in government hospital (Nair et al., 2013). Based on the Ministry of Health gazette published in 2013, the maximum cost for radiotherapy is RM5,720, while consultation cost can range between RM860 and RM1,715. However, the treatment varies on a case-to-case basis, so does the cost. In order to increase the survival rate for NPC patients, some patients and families may choose to go for advanced level of treatments (Nair et al., 2013). Based on the Ministry of Health's cancer survey, the total treatment cost of Nasopharyngeal cancer in Malaysia was reported approximately RM70,000 (Rebecca, 2016).

According to Bernama, due to high treatment and medical spending, 51\% of Malaysian cancer patients suffered from "financial catastrophe" a situation where medical expenses exceed $20 \%$ of the household income in the first 12 months after diagnosis. The survey highlights that $49 \%$ of them have spent all their personal savings while $39 \%$ of all respondents failed to pay for their medication. In fact, $35 \%$ of them were unable to pay for their medical consultation fees while, $22 \%$ of the patients could not pay their house rents and mortgages. As a result, the survey indicates that $19 \%$ of them just discontinued the therapy completely (Bernama, 2015). In particular, the survey highlights that patients who seek treatment in the public hospitals tend to face high out-of-pocket spending due to many health services such as chemotherapy, biopsy, biomarker testing, innovative cancer treatments, and palliative care (Bernama, 2015). Although the government provide free and or subsidized treatment at the tertiary cancer centre, however, the geographical and logistic challenges have become one of the major problems faced by many patients. On the other hand, the Sydney-based George Institute for Global Health research of Asean Costs in Oncology (Action) reports that 44 percent of the respondents would survive cancer without experiencing any financial catastrophe, while another $11 \%$ will die eventually.

Another study was carried out by Ng et al., (2010) in Hong Kong to assess the effectiveness of NPC screening which can be used to improve the survival rate of NPC. Through annual testing with EBV serology test and nasopharyngoscopy, a significant shift in the phase distribution to earlier stage could be achieved. The screening-detected NPC patients who may suffer from stage I illness $(41 \%$ versus $<1 \%)$ and better disease-free survival relative to the symptomatic NPC patients referred to in the same 19 periods (Ng et al., 2010). However, the survival outcomes should not be overestimated owing to small sample size. There is insufficient evidence for people at average risk to suggest a population-based screening system for nasopharyngeal cancer (NPC) using IgA against specific Epstein-Barr virus (EBV) and EBV DNA testing (Wu et al., 2015). For high risk individual, NPC patient's family members may consider seeking advice from physicians before making an informed decision about screening choice. Meanwhile in the U. S. and other countries where NPC rarely occurs, they support regular check-ups and dental visits rather than routine screening (American Cancer Society, 2018)

\section{Data Descriptions and Methodology}

A face-to-face, primary data collection study approach was conducted among 299 nasopharyngeal cancer patients who were admitted at the Radiotherapy and Oncology Unit (RTU) including the Ear, Nose and Throat (ENT), divisions within the Sarawak General Hospital, in Kuching, Sarawak. The study was registered under NMRR Research and was approved by the Medical Research Ethnic Committee (MREC). Before getting the final approval from the Director of Sarawak General Hospital, the team also solicited further endorsement from the Head of RTU and ENT Departments. We recruited subjects from the lists of Nasopharyngeal cancer patients who had been diagnosed and having appointment records with doctors in Sarawak General Hospital (SGH) randomly from 
November 2018 to March 2019.

A professional advisory committee developed for the study provided all the inputs necessary to finalize the study instruments. The survey instrument included questions concerning socio-economic and demographic characteristics, knowledge of cancer diagnosis and treatment facilities, stages of cancer, direct and indirect costs, source of payment, assistance received, constraints faced during treatment etc. As part of the collaborative initiative, the Radiotherapy and Oncology Unit (RTU) and Ear, Nose and Throat (ENT) Departments of the hospital provided the patient's list diagnosed with nasopharyngeal cancer. All respondents were fully notified about the nature of the study and have completed the consent form presented to them. Relevant information was gathered and Microsoft Office Excel and IBM Statistical Package for Social Sciences (SPSS) Statistics version 23 were used to generate various tables for analysis purposes.

It is posited that patients at different stages will likely encounter or go through different pattern's treatment, diagnosis, including in terms of direct and indirect costs as well as the mode of payment. In order to get a more representative average cost at different stages, the average cost for each treatment will be taken from the patients who have actually paid for their treatment costs. Subsequently, the average cost for each treatment will be added up to form the total average cost for treatment. Hence, the average direct cost of the treatment represents an addition for each average cost of surgery, chemotherapy, physiotherapy, radiation therapy, complementary therapy, other direct treatment (like biopsy, blood test, consultation, dental treatment, counter registration, scanning on brain, nose, ear, bones like CT Scan, MRI, X-ray). Given this, direct treatment costs from other medical or surgical illness such as hypertension, osteoporosis anemia, artery inflammation, constipation, coughing, ear swing, eye swollen, face numb, gasping, hair loss, headache, hearing loss, hepatitis B, insomnia, kidney problem, mouth stiff, neck burn, neck stiff, neck swollen, no appetite, no saliva, nose blogged, nose feel hot, oral suspension, poor vision, recurrent of cancer, sensitive nose, smell sense loss, speaking problem, sore throat, tasteless, throat dry, throat tumor, tongue pain, tooth decay, vision blur/loss, vomit, weight loss after the cancer treatment were included from the patients who have experienced in paying for each of the treatments. On the other hand, the average indirect cost represents the addition for each average cost which includes nursing care and day care of dependent, nutritional care and dietary supplements, supporting devices, over-the counter medications, counseling services, accommodation (patient), accommodation (companion), transportation, and other miscellaneous expenses. In this study, the total average cost is the total of average direct and indirect costs.

\section{Results}

From the survey, a total of 197 male patients and 102 of female patients took part in the exercise. This suggests that the male patients account for $65.89 \%$ from the total sampling. Notably, 246 or $82.27 \%$ of the NPC patients are above 40 years old. The study also reveals that 170 or $56.86 \%$ of the NPC patients are Indigenous, followed by Chinese (79 patients) and Malay (50 patients). Among the Indigenous, the Bidayuh community recorded 82 out of 170 patients, 48.24\%), and Iban (74 patients out of 170 patients, $43.53 \%$ ). The data also reveal that $85.95 \%$ of the respondents are married, and only $10.03 \%$ are single, while $2.68 \%$ are widowed with $1.34 \%$ are recorded as divorced. Most of the patients' current status of occupation during the interview are unemployed (96 patients, 32.11\%), 63 or 21.07\% of them are housewife, while 51 or $17.06 \%$ of them are retired. It is also noted that 186 or $62.21 \%$ NPC patients have held various responsibilities in the past which include army, beauty salon, boutique, fireman, police, prisoner officer, security etc. Furthermore, quite a high number of them (27 patients) have worked in agriculture field, followed by education (18 patients) and manufacturing/production (14 patients). In terms of their academic achievement, $90.30 \%$ (270 patients) have pursued up to secondary school level.

The study also discovers that $83.61 \%$ or 250 patients belong to the low-income group who earned below RM2,000 per month while, 256 of them have a household size of more than 3 persons. 15 patients $(5.02 \%)$ recorded as smokers, and 96 patients (32.11\%) are ex-smokers. Out of 188 non-smokers, 69 patients are having family members who are smokers. Most of the patients declared that they are non-drinker (229 respondents), only 53 respondents are occasional social drinker. In addition, there are 57 patients have received traditional/complementary medicine prior to seeking treatment from the hospital. According to the study, a total of 284 patients have to wait between $0-5$ months before they can receive their treatment due to various further investigations while holding back their appointment due to fear and working factors. In fact, 15 patients took between 6-11 months to receive their treatment due to pregnancy, financial problems, alternative treatments and unaware of the seriousness of the disease.

All the patients involved in the study are nasopharyngeal cancer patients who went to the Sarawak General Hospital for diagnosis, treatment or follow up. Most of the patients, 169 or $56.52 \%$ of them only received diagnosis, treatment and follow up in the public hospital while 130 or $43.48 \%$ of the patients have experienced in both private hospital 
and public hospitals. The finding reveals that most of the nasopharyngeal cancer patients were at stage 3 (189 patients or $63.21 \%)$ and stage $4(56$ patients (18.73\%). At stage 2 only recorded 51 patients $(17.06 \%)$ while at stage 1 only has 3 patients $(1.00 \%)$.

Table 1. Total direct and indirect costs incurred by NPC patients

\begin{tabular}{llccccc}
\hline & & Stage 0 & Stage 1 & Stage 2 & Stage 3 & Stage 4 \\
\hline No. of respondents & 169 & 1 & 32 & 26 & 40 & 70 \\
\hline \multirow{3}{*}{ Public Hospital } & Average Direct Cost (RM) & 180 & 2128 & 1840 & 3465 & 3354 \\
& Average Indirect Cost (RM) & 50 & 4325 & 6493 & 9700 & 7870 \\
& Total Average Cost (RM) & 230 & 6453 & 8333 & 13165 & 11224 \\
\hline No. of respondents & 130 & 2 & 19 & 30 & 39 & 40 \\
\hline \multirow{2}{*}{ Private and Public } & Average Direct Cost (RM) & 1538 & 7360 & 22896 & 24541 & 23456 \\
& Average Indirect Cost (RM) & 7544 & 10246 & 18365 & 29384 & 55404 \\
& Total Average Cost (RM) & 9082 & 17606 & 41261 & 53925 & 78860 \\
\hline
\end{tabular}

All the costs involved in this survey are based on each patient's experience hence, the costs were derived based on certain estimations. A comparison in terms of the cost incurred by patients who seek treatment either in both public and private hospitals was carried. In line with this, the spending of patients who only received diagnosis, treatment and follow up in the public hospital, and the costs incurred by patients who went to the private hospital but later referred to the public hospital were ascertained. The costs were analyzed based on per visit and the total spending that have paid by the patients. Table 1 shows the average direct, indirect cost and total costs due to the cancer treatment of NPC patients who only received diagnosis, treatment and follow up in the public hospital with patients who seek treatment in both private and public hospitals at different stages of their treatment.

Table 1 shows the NPC patient who only received diagnosis, treatment and follow up in public hospital. From the table, there are one stage 0 NPC patients, 32 stage 1 NPC patients, 26 stage 2 NPC patients, 40 stage 3 NPC patients and 70 stage 4 NPC patients, respectively. The total average cost (TAC) of NPC patients at stage 0 is RM230 while the average direct cost (ADC) is RM180 with an average indirect cost (AIC) of RM50. This is based on the only one NPC new case patient with stage 0 who are being interviewed hence the average spending that represents stage 0 NPC patient at public hospital is very low. The total average cost of NPC patients increases as the stage of cancer advances, stage 1 (RM6,453), stage 2 (RM8,333) and stage 3 (RM13,165). Notably, there is a decrease in total average cost at stage 4 NPC patient to RM 11,224 compared to previous stage. Besides, the average indirect cost at stage 1 (RM4,325), stage 2 (RM6,493), stage $3(\mathrm{RM} 9,700)$ and stage $4(\mathrm{RM} 7,870)$ are 2 to 3 -fold higher than the average direct cost at stage $1(\mathrm{RM} 2,128)$, stage $2(\mathrm{RM} 1,840)$, stage $3(\mathrm{RM} 3,465)$ and stage $4(\mathrm{RM} 3,354)$ in the public hospital.

In Table 1, patients who received diagnosis, treatment and follow up in both private and public hospitals incurred more compared to those who only received diagnosis, treatment and follow up in the public hospital. The number of patients who received diagnosis, treatment and follow up in public hospital is more than the number of patients who went to both private and public hospitals. There are 2 patients at stage 0,19 patients at stage 1, 30 patients at stage 2 , 39 patients at stage 3,40 patients at stage 4 who received diagnosis, treatment and follow up in both private and public hospitals. The total average cost is increasing as the cancer stage advances. For instance, at stage 0 (RM9,082), stage 1 (RM17,606), stage 2 (RM41,261), stage 3 (RM53,925) and stage 4 (RM78,860), respectively. In Particular, the average direct cost also increases as the stage of cancer continue to advance. For example, at stage 0 (RM1,538), stage 1 (RM7,360), stage 2 (RM22,896) and stage 3 (RM24,541), respectively. However, the average direct cost at stage 4 (RM23456) declines as compared to stage 3. Notably, the average indirect cost also increases as the stage increases. For instance, at stage 0 (RM7,544), stage 1 (RM10,246), stage $2(\mathrm{RM} 18,365)$, stage $3(\mathrm{RM} 29,384)$ and stage 4 (RM55,404). 
Table 2. Sources help to reduce financial burden of NPC patients

\begin{tabular}{lccc}
\hline Source of Reduce Financial Burden & No. of Patients (\%) & Public Hospital & Private and Public Hospital \\
\hline Savings & $216(72.24 \%)$ & 121 & 95 \\
Family Members & $185(61.87 \%)$ & 112 & 73 \\
Others & $97(32.44 \%)$ & 56 & 41 \\
Non-Profit Organization or Charity & $49(16.39 \%)$ & 34 & 15 \\
Medical insurance & $25(8.36 \%)$ & 9 & 16 \\
Company Health Care Benefit Allowance & $23(7.69 \%)$ & 9 & 14 \\
Employees Provident Fund (EPF) & $23(7.69 \%)$ & 14 & 9 \\
Pension & $18(6.02 \%)$ & 8 & 10 \\
Borrow money from relatives or friends & $12(4.01 \%)$ & 6 & 6 \\
Financial Support from Organization & $5(1.67 \%)$ & 3 & 2 \\
Cash from other investments & $3(1.00 \%)$ & 0 & 3 \\
Refinancing / second mortgage on house & $1(0.33 \%)$ & 0 & 1 \\
\hline
\end{tabular}

Table 2 shows that savings (216 patients or $72.24 \%$ ) is the main sources of funding that helps reduce the burden of NPC patients, followed by assistance from family members (185 patients or $61.87 \%$ ), other sources like government, school and hospital subsidies, church, donation, own farming (97 patients or 32.44\%) and Non-Profit Organization or Charity 49(16.39\%). A low percentage of NPC patients also go for Medical insurance 25(8.36\%), Company Health Care Benefit Allowance 23(7.69\%), Employees Provident Fund (EPF) 23(7.69\%), and pension 18(6.02\%). Among patients who received diagnosis, treatment and follow up in public hospital, the sources that help to reduce the NPC patients' financial burden may come from savings (121 patients), family members (112 patients), other financial supports (56 patients), non-profit organization or charity (34 patients), and EPF (14 patients). On the other hand, among patients who received diagnosis, treatment and follow up in both private and public hospitals, the sources help to reduce the financial burden of NPC patients include savings (95 patients), family members (73 patients), other financial support (41 patients), medical insurance (16 patients), and non-profit organization or charity (15 patients). The sources like medical insurance and company health care benefit allowances have high tendency to be used if the patients have subscribed to it.

\section{Discussions}

More than half of the patients reported that they have received diagnosis, treatment and follow up from the public hospital. This clearly reveals that Sarawak General Hospital provides an affordable price with professional cum experienced doctors, nurses, radiotherapist and facilities in handling NPC cases. However, nearly half of the patients reported that they also received diagnosis, treatment and follow up from both private and public hospitals. This is due to the perception of long waiting time to receive treatment in the public hospital forcing patients to visit private facilities. Nasopharyngeal cancer is difficult to be examined clinically due to its non-specific symptoms, patients went to the private health facilities for normal checking. Hence, if the patients have the symptoms of hearing problem on one side of the ear, a painless lump on neck, facial numbness, blood in saliva or nose, including family members who have cancer history and they are under high risk group, they will likely to go to the nearest ear, nose and throat (ENT) specialists instead of general practitioners because they may not have the facilities to detect the illness and delayed the best time for patients to receive treatments. This approach appears to be consistent with the outcomes of the study where potential patients may choose both private and public hospitals at any stages of their treatment.

The study also reports that the high-risk group of nasopharyngeal cancer are males ageing from 41 years old and above, and the disease tends to suffer by mostly Bidayuh, Iban and Chinese community like Hakka, Foochow and Hokkien. They come from different working experiences which include agriculture, education, manufacturing/ production, housewife and soldier. Although most of the NPC patients are not smokers, however, many of their family members are smokers hence, smoking may have contributed to NPC. Even though some of the patient did not have formal education, however, most of the NPC patients possessed secondary school qualifications but earned lower than RM 2,000 a month with large household size. Consequently, the group will likely face financial problem when the family members suffered from the disease. The study also discovered that these group of patients normally 
surrounded by several challenges in terms of communication, financial, travelling and will likely apply for assistance/subsidy. They tend to depend on their family members to bring them to hospital therefore, if their family members have other commitments, they have a tendency to skip some of the treatments. As a result of this, their treatment decision is usually delayed due to various issues and challenges which may include financial problem, further investigation by the hospital concerned, pregnancy, alternative treatment, unaware on the seriousness of the problem, malfunction of facilities and unable to allocate time.

Patients who received diagnosis, treatment and follow up in both private and public hospitals will likely incur more direct costs of the treatment. Recognizing this, many of the patients are referred from the private hospital to the public hospital to enable them to continue the treatment at lower cost. This approach is consistent with the National Cancer Society of Malaysia (NCSM) who argues that the charges for cancer treatment at public hospitals are 50\% $-70 \%$ lower compared to the charges imposed by the private medical institutions (Wong, 2014). Under the fees (Medical) (Amendment) Order 2017 (2017), it is mandatory for patients from private hospitals coming to public hospital to be charged at first-class rates. This law is still applicable in Sarawak General Hospital. However, if the patients have obtained a referrer letter from the doctor of the private hospital and subsequently an approval was granted by the Sarawak General Hospital, hence the patients will enjoy the same rate with other patients who only received their first treatment from the public hospital.

Normally, the average direct cost of cancer patient will increase as the stage of cancer advances. However, the decrease of average direct treatment cost at stage 4 compared to stage 3 is due to the reduction of stage 4 patients in receiving radiation therapy. Normally at stage 3 NPC patients will receive concurrent chemotherapy and radiation therapy to kill and slow down the spreading of cancer while at stage 4, patients with severe conditions will only receive chemotherapy to control and slow down the spreading of cancer.

This study also highlights that the major sources to help reduce the financial burden of patients who received diagnosis, treatment and follow up in both private and public hospitals may come from savings, family members, medical insurance, non-profit organization or charity, including company health care benefit allowances. Patients who have alternative financial supports for their treatment will likely seek treatment from both public and private hospitals while, patients who are financially weak will likely to seek treatment from the public hospital only. Generally, Sarawakians have low income and large household size and this has forced them to unable to seek treatment from the private hospital.

Most importantly, when it comes to critical illnesses, the perception of the public is that the public hospital can handle it better while knowing the fact that the government is providing free/subsidized treatment for the low- and middle-income groups. The outcome of the study also reveals that government continue to play a crucial role in reducing the financial burden of NPC patients. In fact, some of the patients received free charges not because they are poor, but they are public servants, or they are using guarantee letter from their children who are public servants. Although the government provided substantial financial supports in terms of treatment cost, however the geographical condition in Sarawak may result in high travelling and accommodation costs and this may cause seeking treatment in public hospital becomes a burden for the low-income families. Patients who received diagnosis, treatment and follow up in public hospital may spend more on indirect costs compared to direct costs. Hence, the study notes that both the direct and indirect costs in treating cancer has become a big challenge to any poor family in Sarawak. In order to reduce the burden owing to the geographical situation, it would be desirable for the government to include more financial assistance to cover for their accommodation and logistic costs.

\section{Conclusions and Policy Recommendations}

This study has summarized the total average cost of NPC patients who received diagnosis, treatment and follow up in public hospital and both private and public hospital by stages. For public hospital only, the NPC patients can incur up to RM13,165 while for patients who seek treatment in both private and public hospitals, the NPC patients can spend up to RM78,860. The high cost of NPC cases will create an awareness and it will benefit the new NPC patients and the public in terms of decision making about the financial allocation, choice of hospital and treatment choices when dealing with Nasopharyngeal Cancer.

In order to reduce their financial burden, it is necessary to establish a good referral system and framework for health insurance / financial assistance programs, travel and lodging expenses for poor patients.The study demonstrates that the outpatient counter of hospital lacks adequate communication operations about the health insurance / financial support systems. Lack of awareness was the biggest stumbling blocks to reach the poor families about the benefits of financial support. In addition to numerous financial assistance available, there is little knowledge of the schemes among the poor families; they do not know how to apply and assert the benefits provided by the scheme, even if they 
are aware of it. It is necessary to promote understanding of the value of contributing to the health insurance scheme. It is necessary to promote greater understanding of the significance of subscribing to the health insurance system. In fact, doctors and medical staff in the Sarawak General Hospital have been found helping poor patients to submit applications for financial support programs administered by federal, state or NGOs. Effective communication between central, state governments or non-governmental organizations such as SOCSO, EPF and Welfare Department with doctors and patients are crucial as they may provide linkages between patients and these organisations when it comes to application procedures and available schemes/assistances provided by these organisations.

According to the standard set by the World Health Organization, Malaysia as an upper middle-income country should be spending around seven per cent of its Gross Domestic Product (GDP) on healthcare (Jowett et al., 2016). However, Malaysian government only allocates around 4.3 per cent of its GDP to healthcare, out of which 2.3 per cent is spent on public healthcare (Bernama,2018a). Modern technology has proven efficient in the treatment of illnesses, but technology costs money, hence government should allocate more budget on the latest facilities. It is pertinent to note that Sarawak General Hospital need to acquire more radiotherapy machines due to high demand, but the machine is limited and sometimes it fails to function effectively. The machine will benefit not only NPC patients but all cancer types of patients so that the process of treatment did not get interrupted. Malaysia needs to allocate more fund to support the rise of major medical cases while reducing the financial burden of patients.

Notably, nearly $60 \%$ of cancers in Malaysia were diagnosed late because of the low early health screening rate. One of the reasons for late diagnoses could be due to the failure in recognizing and acting on suspicious cancer symptoms by the patients. Nasopharyngeal cancer is a disease that can be prevented and has high 5 years survival rate if it is detected at an early stage. However, in order to increase the survival rate of nasopharyngeal cancer, the most efficient way is to have a policy that can reinforce people's understanding on cancer and how to control it. Nasopharyngeal carcinoma has high incidence rates in certain populations, therefore a population-based nasopharyngeal cancer (NPC) screening programme should be established as patients with early stage of the disease have a much better prognosis. It is time to implement cancer prevention methods, early detection and nasopharyngeal cancer patient care.

\section{Acknowledgements}

Financial support from the Transdisciplinary Research Scheme (TRGS) [F01/TRGS/1521/2016] and Universiti Malaysia Sarawak (UNIMAS) are gratefully acknowledged. The authors would like to thanks the patients involved in the study, and the kind assistance given by Sarawak General Hospital.

\section{References}

Adham, M., Kurniawan, A. N., Muhtadi, A. I., Roezin, A., Hermani, B., Gondhowiardjo, S., ... Middeldorp, J. M. (2012). Nasopharyngeal carcinoma in Indonesia: Epidemiology, incidence, signs, and symptoms at presentation. Chinese Journal of Cancer, 31(4), 185-196. https://doi.org/10.5732/cjc.011.10328

Al-Azri, A., \& Al-Sheibani, S. (2015). Nasopharyngeal Carcinoma in Oman: A descriptive analysis. Oman Medical Journal, 30(3), 167. https://doi.org/10.5001/omj.2015.37

American Cancer Society. (2018). Can Nasopharyngeal cancer be found early? Retrieved from https://www.cancer.org/cancer/nasopharyngeal-cancer/detection-diagnosis-staging/detection.html

Bernama. (2015, September 11). Survey shows nearly half Malaysian cancer patients broke a year after diagnosed. Malaymail. Retrieved

from https://www.malaymail.com/news/malaysia/2015/09/11/survey-shows-nearly-half-malaysian-cancer-patients-br oke-a-year-after-diagn/968201

Bernama. (2018a, December 13). Reason why Malaysia has high cancer mortality rate. Malaymail. Retrieved from https://www.malaymail.com/news/malaysia/2018/12/13/reasons-why-malaysia-has-high-cancer-mortality-rate/1 702830

Bernama. (2018b, September 24). Nasopharyngeal cancer most prevalent among Malaysian Chinese, surgeon says. Malaymail. Retrieved from https://www.malaymail.com/news/malaysia/2018/09/24/nasopharyngeal-cancer-most-prevalent-among-malaysi an-chinese-surgeon-says/1675725

Bray, F., Ferlay, J., Soerjomataram, I., Siegel, R. L., Torre, L. A., \& Jemal, A. (2018). Global cancer statistics 2018 : GLOBOCAN estimates of incidence and mortality worldwide for 36 cancers in 185 countries. CA: A Cancer Journal for Clinicians, 68(6), 394-424. https://doi.org/10.3322/caac.21492 
CEIC. (2016). Malaysia poverty rates: Sarawak. Retrieved from https://www.ceicdata.com/en/malaysia/household-income-and-basic-amenities-survey-poverty-rates/poverty-rat es-sarawak

Department of Statistics Malaysia. (2018). Sarawak Population. Retrieved from http://www.statistics.gov.my

Devi, B. C., Pisani, P., Tang, T. S., \& Parkin, D. M. (2004). High incidence of nasopharyngeal carcinoma in native people of Sarawak, Borneo Island. Cancer Epidemiology and Prevention Biomarkers, 13(3), 482-486.

Fees (Medical) (Amendment) Order 2017. (2017). AGC Federal Gazette. Retrieved from https://www.aseanlip.com/dp.aspx?src=https://www.aseanlip.com/assets/uploads/aseanlic-86857-pua_20170202 _P.U.-(A)-47.pdf\&id=13061

Jong, T. M. S., Puah, C. H., Yeoh C. Y., Brahmana, R. K., \& Wong, S. S. L. (2019). Financial Impact of Cancer Treatment: An empirical study in Kuching. International Journal of Science and Technology Research, 1(1), 1374-1378.

Jowett, M., Brunal, M. P., Flores, G., \& Cylus, J. (2016). Spending targets for health: No magic number. World Health Organization. Retrieved from https://apps.who.int/iris/bitstream/handle/10665/250048/WHO-HIS-HGF-HFWorkingPaper-16.1-eng.pdf?seque nce $=1$

Kheung, L. C., \& Adruce, S. A. Z. (2018). The demographic profile and sustainability growth of the Bidayuh population of Sarawak. International Journal of Academic Research in Business and Social Sciences, 8(14), 69-78. https://doi.org/10.6007/IJARBSS/v8-i14/5028

Lau, R. (2017, October 29). Time is of the essence in treating nasopharyngeal cancer. Borneo Post Online. Retrieved from http://www.theborneopost.com/2017/10/29/time-is-of-the-essence-in-treating-nasopharyngeal-cancer/

Lau, R. (2018, September 25). Nose cancer a major concern. Borneo Post Online. Retrieved from https://www.theborneopost.com/2018/09/25/nose-cancer-a-major-concern/

Lim, G. C. C. (2002). Overview of Cancer in Malaysia. Japanese Journal of Clinical Oncology, 32(suppl_1), S37-S42. https://doi.org/10.1093/jjco/hye132

Mai, Z. M., Lin, J. H., Ip, D. K. M., Ho, S. Y., Chan, Y. H., \& Lam, T. H. (2019). Epidemiology and Population Screening. In Nasopharyngeal Carcinoma (pp. 65-84). Academic Press.

Malaysian study on cancer survival (MySCan). (2018). National Cancer Registry. Retrieved from http://nci.moh.gov.my/index.php/ms/list-penerbitan/35-laporan/522-myscan

Ministry of Health Malaysia. (2015). Malaysian National Cancer Registry Report 2007-2011. Kuala Lumpur: National Cancer Registry.

Mossanen, M., \& Gore, J. L. (2014). The burden of bladder cancer care: Direct and indirect costs. Current Opinion in Urology, 24(5), 487-491. https://doi.org/10.1097/MOU.0000000000000078

Nair, K. S., Raj, S., Tiwari, V. K., \& Piang, L. K. (2013). Cost of treatment for cancer: experiences of patients in public hospitals in India. Asian Pacific Journal of Cancer Prevention, 14(9), 5049-5054. https://doi.org/10.7314/apjcp.2013.14.9.5049

National Registry of Diseases Office. (2015). Cancer survival in Singapore (1973-2012). Retrieved from https://www.nrdo.gov.sg/docs/librariesprovider3/default-document-library/cancer-survival-in-singapore-1973-2 012-web_28-june.pdf?sfvrsn=5ab861e4_0

Ng, W. T., Choi, C. W., Lee, M. C., Law, L. Y., Yau, T. K., \& Lee, A. W. (2010). Outcomes of nasopharyngeal carcinoma screening for high risk family members in Hong Kong. Familial Cancer, 9(2), 221-228. https://doi.org/10.1007/s10689-009-9296-y

Radiotherapy and Oncology Unit. (2018). Cancer statistics 2018. Sarawak General Hospital. Retrieved from http://hus.moh.gov.my/bm/perkhidmatan/sokongan-klinikal/radioterapi-onkologi-palliative-care/

Rebecca, S. (2016). Is your medical insurance plan sufficient for the big $c$ ? Retrieved from https://www.imoney.my/articles/is-your-medical-insurance-plan-sufficient-for-the-big-c

Sedek, M. (2019). Medical inflation. Retrieved from https://infocus.wief.org/medical-inflation/

Sherman, E. J., Pfister, D. G., Ruchlin, H. S., Rubin, D. M., Radzyner, M. H., Kelleher, G. H., .. Scher, H. I. (2001). 
The collection of indirect and nonmedical direct costs (COIN) form: A new tool for collecting the invisible costs of androgen independent prostate carcinoma. Cancer, 91(4), 841-853. https://doi.org/10.1002/1097-0142(20010215)91:4<841::AID-CNCR1072>3.0.CO;2-B

Tiong, T. S., \& Selva, K. S. (2005). Clinical presentation of nasopharyngeal carcinoma in Sarawak Malaysia. Medical Journal of Malaysia, 60(5), 624.

Ubel, P. A. (2010). Beyond costs and benefits: Understanding how patients make health care decisions. The Oncologist, 15(1), 5-10. https://doi.org/10.1634/theoncologist.2010-S1-5

Wong, P. M. (2014, November 11). Affordable cancer treatment for the poor. The Star Online. Retrieved from https://www.thestar.com.my/news/community/2014/12/11/affordable-cancer-treatment-for-the-poor-ngos-help-e ase-burden-of-hefty-medical-expenses/

World Health Organization. (2018). Cancer. Retrieved from https://www.who.int/news-room/fact-sheets/detail/cancer

Wu, S., Zhou, J., Chen, X. Y., \& Yang, S. (2015). Screening for nasopharyngeal cancer. The Cochrane Database of Systematic Reviews, 11, 15. https://doi.org/10.1002/14651858.CD008423.pub2

Wu, Z. X., Xiang, L., Rong, J. F., He, H. L., \& Li, D. (2016). Nasopharyngeal carcinoma with headaches as the main symptom: A potential diagnostic pitfall. Journal of Cancer Research and Therapeutics, 12(1), 209. https://doi.org/10.4103/0973-1482.157334

Yeo, G. G., Beh, S. P., Tan, C. K., \& Pei Jye, V. (2018). 323P Strong family history of nasopharyngeal carcinoma (NPC) in Bidayuh, a local native group in Sarawak, Malaysia. Annals of Oncology, 29(suppl_9), 94-104. https://doi.org/10.1093/annonc/mdy438.017

Zeng, H., Chen, W., Zheng, R., Zhang, S., Ji, J. S., Zou, X., ... Wang, N. (2018). Changing cancer survival in China during 2003-15: A pooled analysis of 17 population-based cancer registries. The Lancet Global Health, 6(5), 555-567. https://doi.org/10.1016/S2214-109X(18)30127-X 